\title{
Cutaneous Vasculitis and Digital Ischaemia Caused by Heterozygous Gain-of-Function Mutation in C3
}

\author{
Ebun Omoyinmi ${ }^{1,2 \star}$, Iman Mohamoud ${ }^{1}$, Kimberly Gilmour ${ }^{3}$, Paul A. Brogan ${ }^{1,2}$ and \\ Despina Eleftheriou ${ }^{1,2,4}$ \\ ${ }^{1}$ Infection, Inflammation and Rheumatology Section, UCL Great Ormond Street Institute of Child Health, London, \\ United Kingdom, ${ }^{2}$ Great Ormond Street Hospital NHS Foundation Trust, London, United Kingdom, ${ }^{3}$ Clinical Immunology \\ Laboratory, Great Ormond Street Hospital NHS Foundation Trust, London, United Kingdom, ${ }^{4}$ Centre for Adolescent \\ Rheumatology, Arthritis Research UK, University College London (UCL), University College London Hospital (UCLH) and \\ Great Ormond Street Hospital (GOSH), London, United Kingdom
}

It is now increasingly recognized that some monogenic autoinflammatory diseases and immunodeficiencies cause vasculitis, although genetic causes of vasculitis are extremely rare. We describe a child of non-consanguineous parents who presented with cutaneous vasculitis, digital ischaemia and hypocomplementaemia. A heterozygous p.R1042G gain-of-function mutation (GOF) in the complement component C3 gene was identified as the cause, resulting in secondary C3 consumption and complete absence of alternative complement pathway activity, decreased classical complement activity, and low levels of serum C3 with normal C4 levels. The same heterozygous mutation and immunological defects were also identified in another symptomatic sibling and his father. C3 deficiency due GOF C3 mutations is thus now added to the growing list of monogenic causes of vasculitis and should always be considered in vasculitis patients found to have persistently low levels of C3 with normal C4.

Keywords: cutaneous vasculitis, digital ischaemia, autoinflammation, gain-of-function (GOF), next-generating sequencing, targeted gene capture, complement component (C3, C4)

\section{BACKGROUND}

The complement system is an important component of the innate immune system, with several versatile functions in host defense, immune surveillance, and cell homeostasis (1-3). Deficiencies of individual complement proteins and complement regulatory proteins are associated with increased risk of infection, and in some cases autoimmunity $(4,5)$. C3 deficiency is very rare, with less than 50 cases described worldwide with varied clinical presentation (6-8). Primary C3 deficiency due to bi-allelic loss of function mutations in C3 is typically associated with increased susceptibility to bacterial infections (such as bacterial pneumonia or meningitis) often manifesting in early childhood; and/or development of immune complex-mediated diseases such as glomerulonephritis (9-12). Additionally, polymorphisms in the C3 gene may confer an increased risk for the development of age-related macular degeneration, atypical hemolytic uremic syndrome (aHUS), dense deposit glomerulonephritis (13-16), or influence outcomes of organ transplantation $(17,18)$. Whilst reduced plasma C3 is commonly observed with concomitant reduction in C4 due to classical pathway activation, for example secondary to autoimmune diseases such as systemic lupus erythematosus, low plasma C3 with relative conservation of $\mathrm{C} 4$ is typical of alternative 
pathway activation, and should always prompt further investigation for monogenic causes $(19,20)$. These include bi-allelic loss of function mutations in C3, or complement factor I (CFI) (19), but can also be caused by mono allelic gain-offunction (GOF) C3 mutation $(13,21,22)$. Vasculitis caused by GOF mutation in $\mathrm{C} 3$ has never been reported before, however. Herein, we describe a child of non-consanguineous parents who presented with cutaneous vasculitis, digital ischaemia and hypocomplementaemia. A heterozygous p.R1042G GOF mutation of $C 3$ was identified as the cause, resulting in complete absence of alternative complement pathway activity, reduced classical complement activity, and low levels of C3 with normal C4 levels.

\section{CASE PRESENTATION}

The index case was a previously well 6-year-old male, born to non-consanguineous Caucasian parents (family tree, Figure 1A). He spontaneously developed acute, painful erythema and discoloration of his fingers and toes (Figures 2A-C). There were no reported precipitants, specifically no evidence of any intercurrent infection, and no past medical history suggestive of immunodeficiency. On systems review, he reported intermittent non-peritonitic abdominal pain, and arthralgia of knees and ankles. He rapidly deteriorated over the next $48 \mathrm{~h}$, developing critical digital ischaemia of his toes (Figures 2D,E).

Laboratory investigations (Supplemental Table 1) in the proband revealed normal renal function and blood pressure, and there was no evidence of proteinuria or other organ specific involvement. Chest radiograph, abdominal ultrasonography, echocardiography, and visceral digital subtraction catheter arteriography were all normal. There was only minor elevation of the erythrocyte sedimentation rate $(13 \mathrm{~mm} /$ hour; reference range [RR] 0-10), and normal C-reactive protein (CRP) $<5 \mathrm{mg} / \mathrm{L}$ $(\mathrm{RR}<20)$. All full blood count parameters were normal. Blood film examination was unremarkable. He had low titer antinuclear antibodies (1:160). Other autoantibodies (rheumatoid factor, ANCA, including anti-proteinase 3 and anti-myeloperoxidase; anti-double stranded DNA; anticardiolipin antibodies and lupus anticoagulant; thyroid peroxidase antibodies; and antibodies against extractable nuclear antigens) were all negative. Extensive investigations for an infectious cause of his symptoms were negative, specifically negative mycoplasma pneumoniae serology; and he had negative cryoglobulins. A full prothrombotic workup was also negative. Notably, however, he had persistently low serum C3 (0.22 g/L; RR 0.75-1.65), and normal C4 (0.21 g/L; RR 0.14-0.54); complete absence of alternative complement functional activity $(0 \%, \mathrm{RR}>10 \%)$; and reduced functional classical pathway activity (31\%; RR $>40 \%$; Table 1 ). Low C3, normal C4, absent alternative complement pathway activity, and markedly decreased classical complement pathway activity persisted, and prompted more detailed scrutiny of the complement pathway (see below for complement deficiency work up). Vasodilatory treatment for critical digital ischaemia included oral nifedipine $40 \mathrm{mg}$ /day with little response, and subsequently prostacyclin infusion $(20 \mathrm{ng} / \mathrm{mg} / \mathrm{min}$ continuous infusion over 5 days) to improve the perfusion in his toes. $\mathrm{He}$ was also treated with a short course of oral prednisolone (2 $\mathrm{mg} / \mathrm{kg} /$ day; weaning over 12 weeks), aspirin ( $5 \mathrm{mg} / \mathrm{kg} /$ day) and oral azathioprine $(2 \mathrm{mg} / \mathrm{kg} /$ day $)$, on which he currently remains 12 months later. He made a full recovery with no residual skin lesions or permanent tissue loss. Corticosteroids however were reintroduced with good response 13 months later as there was recurrence of finger ischaemia.. C3 remains persistently decreased $0.22 \mathrm{~g} / \mathrm{L}$, with normal C4 $0.27 \mathrm{~g} / \mathrm{L}$ despite ongoing treatment.

\section{Work Up for Suspected Complement Deficiency}

Table 1 summarizes the genotype and results of complement studies. All experimental work was performed with ethical approval (ethics number: 08H071382) and with written informed consent from all adult participants, assent (where appropriate) for children, and parental consent for children. C3 and C4 measurements were performed using a standard nephelometry assay (BN II Siemens Healthcare UK). Classical and alternative complement assays (EuroDiagnostics, Sweden); MBL assays (BioPorto) were performed by enzyme-linked immunosorbent assay (ELISA). Complement factor $\mathrm{I}$ and $\mathrm{H}$ were measured at Pathology Imperial College Healthcare, NHS, UK using ELISA (Binding Site, UK). C1q was measured by radial immunodiffusion (RID) and C1q antibodies by ELISA at the Protein Reference Unit Sheffield, UK.

Genetic investigation of the index case (II-1) was performed using our recently developed targeted gene panel for Vasculitis and AutoInflammation Panel (VIP) that contains 201 genes, including 19 pertaining to complement and regulatory proteins (Supplemental Table 2) (23). This revealed a heterozygous c.3124C > G (p.R1042G) variant in exon 24 of C3 gene, which was confirmed by Sanger sequencing (Figure 1B). This variant is not reported in the population databases (1000 genomes, ESP 6500, and ExAC) and is predicted to be damaging according to 3 different in silico analysis; SIFT [D], PolyPhen2 [D], and MutationTaster [D]. There were no other class 4 or 5 genetic variants detected in any of the other genes included in the targeted panel for the index case.

Detailed complement studies were undertaken in other first-degree family members and showed low C3 levels, absent alternative complement pathway activity, and markedly decreased classical complement pathway activity in II-2 and I-1. These studies were normal for I-2 and II-3 (Table 1). Sanger sequencing in all enrolled family members confirmed that the heterozygous p.R1042G C3 mutation was also present in both II-2 and I-1 and absent in I-2 and II-3 (Figures 1A,B). Interestingly I-1 subsequently developed recurrent cutaneous vasculitis (purpuric rashes) and arthralgia (Figure 2F) with no documented renal abnormalities and required corticosteroid therapy. II-2 was also reporting long standing history of recurrent fingertip erythema with no other systemic symptoms while I-2 and II-3 were asymptomatic (see Supplemental Table 2 for other laboratory tests for I-1 and II-2). 
A

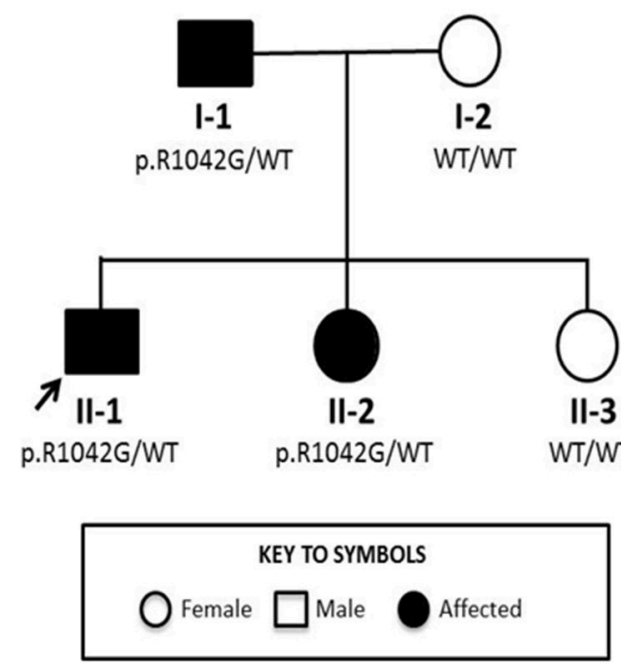

B

$1-1$

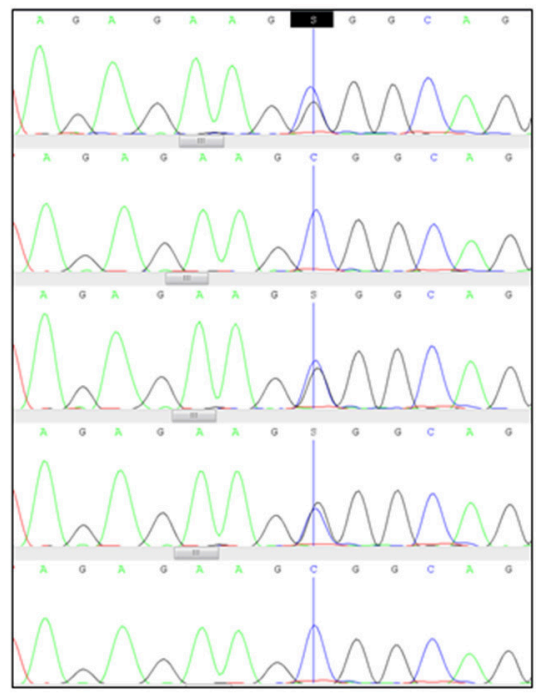

FIGURE 1 | Family tree and Sanger sequencing results. (A) Family tree showing affected and unaffected members enrolled in the study; segregation of the p.R1042G mutation in C3 with disease is also indicated. Arrow indicates the index case. (B) Sanger sequencing confirmed a heterozygous C/G mutation (blue/black overlapping line) at position c.C3124 of C3 gene in family members II-1, I-1, and II-2 that is absent (single blue line corresponding to wild type "C" allele) in I-2 and II-3.

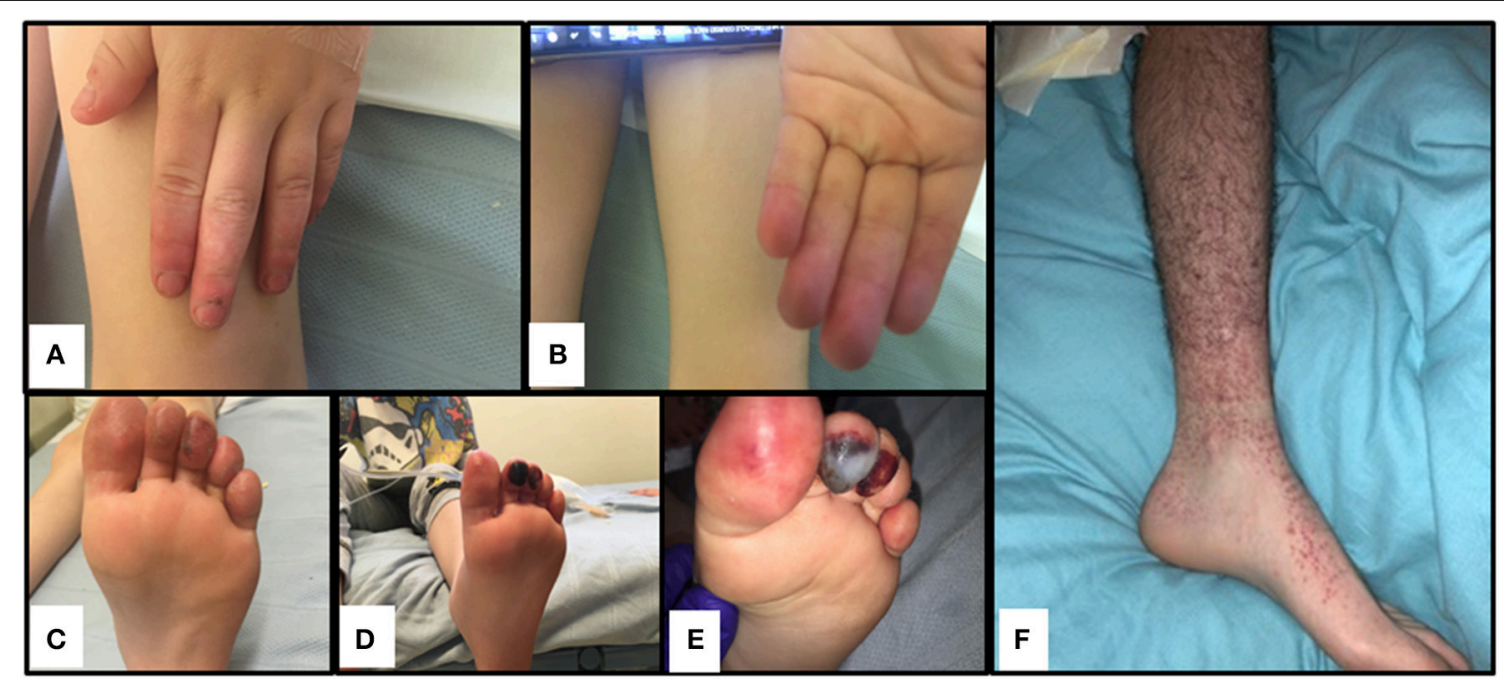

FIGURE 2 | Cutaneous vasculitis and digital ischaemia associated with heterozygous gain-of-function mutation in C3. (A-C). Discolouration and erythema in fingers of both hands and toes of the index case (II-1). (D,E). Digital ischaemic necrosis seen in the second and third digit of the left foot for II-1. (F) Cutaneous vasculitis affecting I-1.

\section{DISCUSSION}

We describe a monoallelic p.R1042G mutation in $C 3$ as the genetic cause of familial cutaneous vasculitis and severe digital ischaemia. This mutation has been previously described as a GOF mutation, associated with glomerulonephritis (24). The presentation in our patient with digital vasculitis and ischaemia is therefore unique, and the vasculitic features in other family members who had the same mutation and immunophenotype emphasizes that this is a fully penetrant dominant mutation in this kindred. Thus the spectrum of monogenic vasculitis continues to expand, and mono-allelic C3 GOF mutations should now be considered in patients with ANCA negative vasculitis, particularly when associated with low serum C3, but normal C4 levels.

During the activation process of the alternative complement pathway, C3 undergoes large conformational changes following the release of $\mathrm{C} 3 \mathrm{a}$ by $\mathrm{C} 3$ convertase, thereby exposing the 


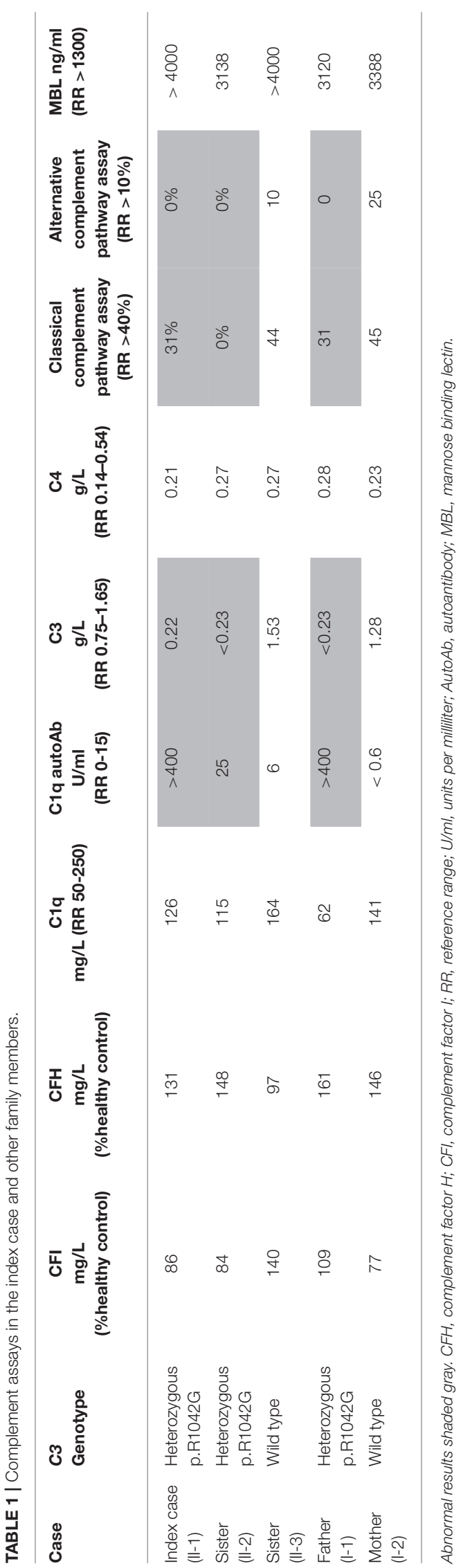

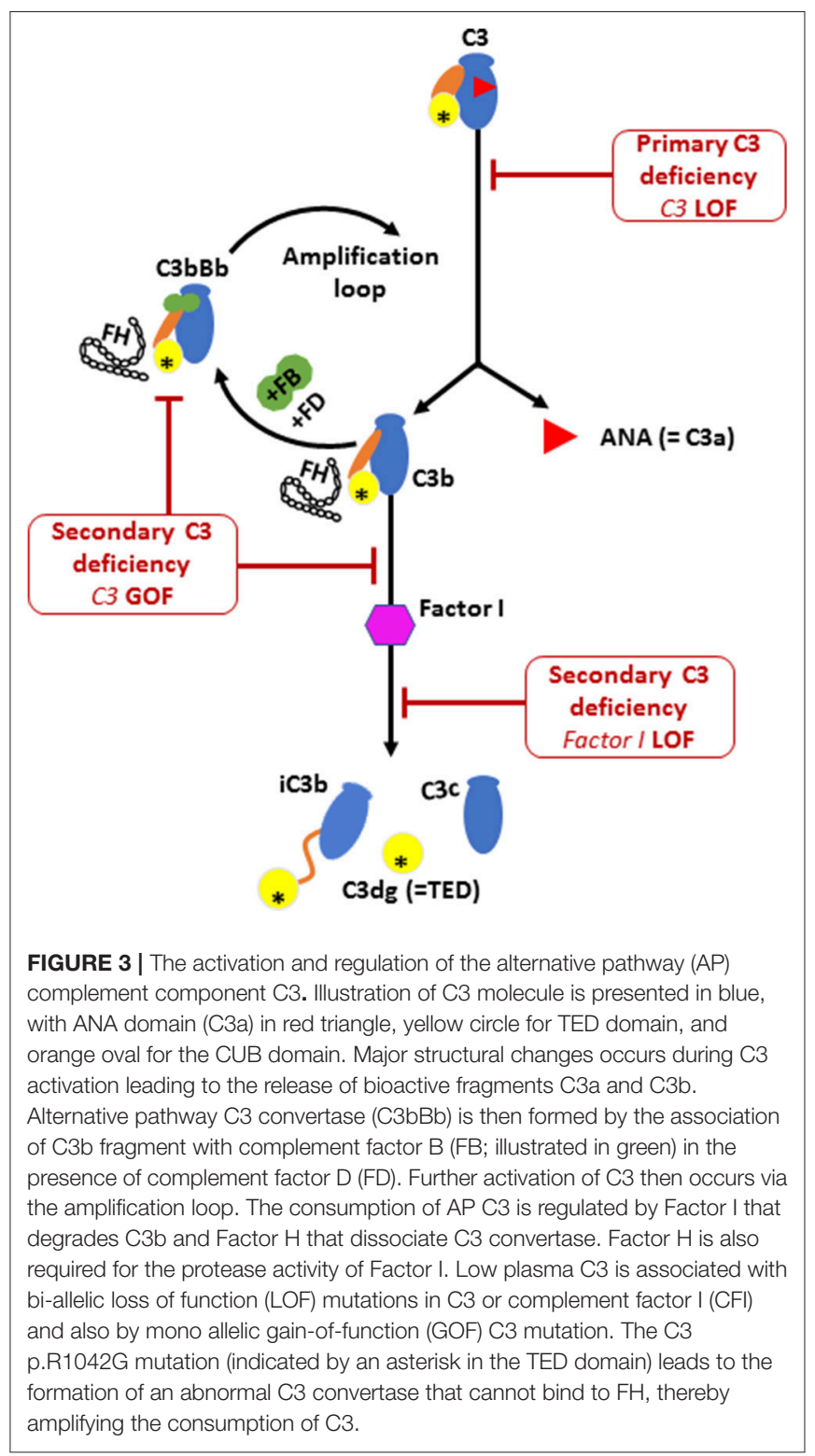

reactive thio-ester containing domain (TED) on the $\mathrm{C} 3 \mathrm{~b}$ fragment (Illustrated in Figure 3). The TED on C3b can then rapidly covalently bind to nucleophiles on cell surfaces (25). Attachment of the C3b fragment to cell surfaces initiates a powerful amplification reaction, by interaction with factor $\mathrm{B}$, factor D and properdin, leading to the formation of more C3 convertases that use plasma C3 as a substrate $(26,27)$. This positive feedback amplification loop, if dysregulated, results in rapid and uncontrolled consumption of C3, with major impact on the alternative complement pathway (28, 29), and relative sparing of the classic pathway which can function with much lower levels of $\mathrm{C} 3$ than the alternative pathway (19). The heterozygous p.R1042G C3 mutation in our patients is predicted to affect the active TED in the C3 protein. Structural studies have demonstrated that this mutation is positioned within the interacting interface of $\mathrm{C} 3$ 
TED domain with Factor $\mathrm{H}$ consecutive complement control protein (CCP) domains, thereby inhibiting the regulatory binding of $\mathrm{FH}$ to the alternative pathway $\mathrm{C} 3$ convertase (i.e., $\mathrm{C} 3 \mathrm{bBb})$ to suppress the amplification loop $(30,31)$. Thus, the p.R1042G C3 mutation is predicted to reduce plasma C3 levels by generating abnormal alternative pathway $\mathrm{C} 3$ convertases $(\mathrm{C} 3 \mathrm{bBb})$ which cannot be inactivated by $\mathrm{FH}$, and leading to rapid consumption of the normal C3 encoded by the normal allele $(24,30)$.

The heterozygous p.R1042G C3 mutation we identified in our kindred was previously described in a single case of a 45 year old Spanish male patient who developed mild proteinuria and microscopic haematuria, but who had no other symptoms or cutaneous manifestations (24). At the time of writing, none of our patients have yet developed renal involvement, but close monitoring of blood pressure, renal function and urinalysis has been initiated in all family members with the heterozygous p.R1042G C3 genotype. Whether renal histopathological abnormalities precede the development of more typical renal function abnormalities could not be established for our cases since a renal biopsy was not clinically indicated or justifiable. Of note, II-2, also heterozygote for the p.R1042G GOF C3 mutation, has abnormal alternative and classical complement function, and low C3 levels but is currently presenting with a milder phenotype suggesting some variability in the type of clinical manifestations associated with GOF C3 mutation. Additional genetic and/or environmental risk factors (such as intercurrent infection or other trigger) may play a role in modifying the observed phenotype. It is likely that complement regulatory molecules act as a protein network and that multiple hits, probably involving plasma and membrane associated complement regulatory proteins, are required to significantly impair protection to host tissues. As such an individual's complotype could influence susceptibility to, or severity of, diseases such as C3 deficiency (31-34).

Therapeutic options for the inflammatory manifestations associated with GOF $\mathrm{C} 3$ mutations and resultant secondary C3 deficiency are very limited, but so far our index case has remained stable on treatment with vasodilation, antiaggregation (aspirin) and immunosuppression. Since the effects of complement are associated with inflammatory sequelae (such as vasculitis) but also possible immune deficiency, we chose a medium strength immunosuppressant to ultimately work alongside corticosteroids eventually working as steroid sparing agent. More targeted complement-modulating agents such as eculizumab, or avacopan might be worthy of consideration, albeit with a limited scientific rationale/evidence-base. Eculizumab is a humanized monoclonal antibody that binds C5 and prevents assembly of the membrane attack complex (C5b-9) thereby blocking the final complement cascade and reducing uncontrolled activation of the alternative complement pathway (35). Several case reports and open-label studies have already shown a potential benefit of eculizumab for patients with C3 glomerulonephritis and aHUS where there is an acquired dysregulation of complement factors (35-38). In addition, avacopan, a C5a receptor inhibitor, downregulates activation of the alternative complement pathway and has been shown to be an effective add-on therapy for ANCA associated vasculitis $(39,40)$. Therefore, these complement modulating agents may also have a role in treating autoimmunity/autoinflammation associated with GOF C3 mutations via reduction of uncontrolled activation of the alternate complement pathway. An alternative approach would be to use plasma exchange to remove dysfunctional C3. However, membrane-bound abnormal C3, which is responsible for alternative pathway activation, cannot be eliminated by plasma exchange, and continued supplementation of C3 may enhance further complement activation. Lastly, for other cases of C3 deficiency secondary to genetic defects affecting the complement regulatory proteins factor $\mathrm{H}$ and $\mathrm{I}$, orthotopic liver transplantation has also been trialed albeit with variable success, given that these proteins are mainly produced in the liver. Such an approach, however, is unlikely to be relevant for patients with GOF C3 mutations given that C3 is not only synthesized in the liver but is also synthesized by immune cells (41), adipocytes (42), and neuronal cells (43).

We felt that our patients suffered cutaneous vasculitis despite the lack of confirmatory biopsy findings. It is now well accepted that histological confirmation is not needed to diagnose vasculitis (44), and that clinical diagnoses based on a sound understanding of pathogenesis (in this case consumptive C3 disease from C3 gain of function and presumed immune complex formation injury to small vessels in the peripheries) provides justification to describe this as a vasculitis. In addition, the father (I-1) developed palpable purpura (see Figure 2F) and typical vasculitic lesions and has an ESR of $65 \mathrm{~mm} / \mathrm{h}$ (see Supplemental Table 1); the sibling II-2 with more minor symptoms of the fingers also has an elevated ESR of $60 \mathrm{~mm} / \mathrm{h}$, confirming the inflammatory component to this pathology.

Lastly, we cannot completely exclude the possibility that antiC1q antibodies might play some secondary role in (II-1 and I1) to explain the observed phenotype, although their presence may represent a non-specific epiphenomenon secondary to chronically increased complement activation, particularly in view of normal $\mathrm{C} 1 \mathrm{q}$ levels observed in these individuals, and the fact that C1q antibodies have also been observed non-specifically in complement factor deficiency (19).

In summary, we expand the spectrum of monogenic complement deficiencies that cause vasculitis by describing a family with monoallelic p.R1042G mutation in C3 causing cutaneous vasculitis and digital ischaemia. Heterozygous GOF mutations in $\mathrm{C} 3$ are now added to the list of genetic complement deficiencies causing vasculitis such as $\mathrm{Clq}, \mathrm{C} 1 \mathrm{r}$, and $\mathrm{C} 1 \mathrm{~s}$ deficiency, complement factor I deficiency and complement C2 and $\mathrm{C} 4$ deficiency $(1,7,19)$. The therapeutic role of complement inhibition therapies to prevent or reduce tissue damage caused by dysregulated complement activation in this setting remains to be established.

\section{ETHICS STATEMENT}

Written informed consent was obtained from the participants for the publication of this report. 


\section{AUTHOR CONTRIBUTIONS}

$\mathrm{EO}, \mathrm{PB}$, and $\mathrm{DE}$ : design of the work, acquisition and analysis of data, drafting and revising manuscript, providing approval for publication; IM: acquisition and analysis of data, providing approval for publication; KG: acquisition and analysis of data, revising manuscript, providing approval for publication.

\section{FUNDING}

This work is funded in part from institutional grants from Rosetrees Trust and Swedish Orphan Biovitrum AB (publ) $\left(\right.$ Sobi $\left.^{\mathrm{TM}}\right)$. DE is funded by Arthritis Research UK (grant 20164).

\section{REFERENCES}

1. Ricklin D, Hajishengallis G, Yang K, Lambris JD. Complement: a key system for immune surveillance and homeostasis. Nat Immunol. (2010) 11:785-97. doi: 10.1038/ni.1923

2. Erdei A, Sándor N, Mácsik-Valent B, Lukácsi S, Kremlitzka M, Bajtay Z. The versatile functions of complement C3-derived ligands. Immunol Rev. (2016) 274:127-40. doi: 10.1111/imr.12498

3. Noris M, Remuzzi G. Overview of complement activation and regulation. Semin Nephrol. (2013) 33:479-92. doi: 10.1016/j.semnephrol.2013.08.001

4. Markiewski MM, Lambris JD. The role of complement in inflammatory diseases from behind the scenes into the spotlight. Am J Pathol. (2007) 171:715-27. doi: 10.2353/ajpath.2007.070166

5. Ricklin D, Reis ES, Lambris JD. Complement in disease: a defence system turning offensive. Nat Rev Nephrol. (2016) 12:383-401. doi: 10.1038/nrneph.2016.70

6. Reis ES, Falcão DA, Isaac L. Clinical aspects and molecular basis of primary deficiencies of complement component C3 and its regulatory proteins factor I and factor H. Scand J Immunol. (2006) 63:15568.doi: 10.1111/j.1365-3083.2006.01729.x

7. Degn SE, Jensenius JC, Thiel S. Disease-causing mutations in genes of the complement system. Am J Hum Genet. (2011) 88:689-705. doi: 10.1016/j.ajhg.2011.05.011

8. Skattum L, van Deuren M, van der Poll T, Truedsson L. Complement deficiency states and associated infections. Mol Immunol. (2011) 48:1643-55. doi: 10.1016/j.molimm.2011.05.001

9. Alper CA, Colten HR, Gear JS, Rabson AR, Rosen FS. Homozygous human C3 deficiency. The role of C3 in antibody production, C-1s-induced vasopermeability, and cobra venom-induced passive hemolysis. J Clin Invest. (1976) 57:222-9.

10. Figueroa JE, Densen P. Infectious diseases associated with complement deficiencies. Clin Microbiol Rev. (1991) 4:359-95. doi: 10.1128/CMR.4.3.359

11. Pickering MC, Botto M, Taylor PR, Lachmann PJ, Walport MJ. Systemic lupus erythematosus, complement deficiency, and apoptosis. Adv Immunol. (2000) 76:227-324. doi: 10.1186/ar301

12. Macedo ACL, Isaac L. Systemic lupus erythematosus and deficiencies of early components of the complement classical pathway. Front Immunol. (2016) 7:55. doi: 10.3389/fimmu.2016.00055

13. Frémeaux-Bacchi V, Miller EC, Liszewski MK, Strain L, Blouin J, Brown $\mathrm{AL}$, et al. Mutations in complement C3 predispose to development of atypical hemolytic uremic syndrome. Blood (2008) 112:4948-52. doi: 10.1182/blood-2008-01-133702

14. Martínez-Barricarte R, Heurich M, Valdes-Cañedo F, Vazquez-Martul E, Torreira E, Montes T, et al. Human C3 mutation reveals a mechanism of dense deposit disease pathogenesis and provides insights into complement activation and regulation. J Clin Invest. (2010) 120:3702-12. doi: $10.1172 /$ JCI43343

15. Thakkinstian A, McKay GJ, McEvoy M, Chakravarthy U, Chakrabarti S, Silvestri G, et al. Systematic review and meta-analysis of the association
The authors declare no conflicts of interest. All research at Great Ormond Street Hospital NHS Foundation Trust and UCL Great Ormond Street Institute of Child Health is made possible by the NIHR Great Ormond Street Hospital Biomedical Research Center. The views expressed are those of the author(s) and not necessarily those of the NHS, the NIHR or the Department of Health.

\section{SUPPLEMENTARY MATERIAL}

The Supplementary Material for this article can be found online at: https://www.frontiersin.org/articles/10.3389/fimmu. 2018.02524/full\#supplementary-material

between complement component 3 and age-related macular degeneration: a HuGE review and meta-analysis. Am J Epidemiol. (2011) 173:1365-79. doi: 10.1093/aje/kwr025

16. Siomou E, Gkoutsias A, Serbis A, Kollios K, Chaliasos N, FrémeauxBacchi V. aHUS associated with C3 gene mutation: a case with numerous relapses and favorable 20-year outcome. Pediatr Nephrol. (2016) 31:513-7. doi: 10.1007/s00467-015-3267-3

17. Brown KM, Kondeatis E, Vaughan RW, Kon SP, Farmer CKT, Taylor JD, et al. Influence of donor C3 allotype on late renal-transplantation outcome. N Engl J Med. (2006) 354:2014-23. doi: 10.1056/NEJMoa052825

18. Goldberg M, Fremeaux-Bacchi V, Koch P, Fishelson Z, Katz Y. A novel mutation in the $\mathrm{C} 3$ gene and recurrent invasive pneumococcal infection: a clue for vaccine development. Mol Immunol. (2011) 48:1926-31. doi: 10.1016/j.molimm.2011.05.020

19. Nanthapisal S, Eleftheriou D, Gilmour K, Leone V, Ramnath R, Omoyinmi E, et al. Cutaneous vasculitis and recurrent infection caused by deficiency in complement factor I. Front Immunol. (2018) 9:735. doi: 10.3389/fimmu.2018.00735

20. Noris M, Ruggenenti P, Perna A, Orisio S, Caprioli J, Skerka C, et al. Hypocomplementemia discloses genetic predisposition to hemolytic uremic syndrome and thrombotic thrombocytopenic purpura role of factor $\mathrm{H}$ abnormalities. J Am Soc Nephrol. (1999) 10:281-93.

21. Lhotta K, Janecke AR, Scheiring J, Petzlberger B, Giner T, Fally V, et al. A large family with a gain-of-function mutation of complement $\mathrm{C} 3$ predisposing to atypical hemolytic uremic syndrome, microhematuria, hypertension and chronic renal failure. Clin J Am Soc Nephrol CJASN (2009) 4:1356-62. doi: 10.2215/CJN.06281208

22. Roumenina LT, Frimat M, Miller EC, Provot F, Dragon-Durey M-A, Bordereau $\mathrm{P}$, et al. A prevalent C3 mutation in aHUS patients causes a direct C3 convertase gain of function. Blood (2012) 119:4182-91. doi: 10.1182/blood-2011-10-383281

23. Omoyinmi E, Standing A, Keylock A, Price-Kuehne F, Melo Gomes $\mathrm{S}$, Rowczenio D, et al. Clinical impact of a targeted next-generation sequencing gene panel for autoinflammation and vasculitis. PLoS ONE (2017) 12:e0181874. doi: 10.1371/journal.pone.0181874

24. Jiménez-Reinoso A, Marin AV, Subias M, López-Lera A, Román-Ortiz E, Payne K, et al. Human plasma C3 is essential for the development of memory B, but not T, lymphocytes. J Allergy Clin Immunol. (2018) 141:1151.e14. doi: $10.1016 /$ j.jaci.2017.09.037

25. Janssen BJC, Christodoulidou A, McCarthy A, Lambris JD, Gros P. Structure of $\mathrm{C} 3 \mathrm{~b}$ reveals conformational changes that underlie complement activity. Nature (2006) 444:213-6. doi: 10.1038/nature05172

26. Lachmann PJ. Chapter 4 - The Amplification Loop of the Complement Pathways. In: Alt FW, editor. Advances in Immunology. Academic Press (2009) p. 115-49. Available online at: http://www.sciencedirect.com/science/ article/pii/S0065277608040042

27. Merle NS, Church SE, Fremeaux-Bacchi V, Roumenina LT. Complement system part I - molecular mechanisms of activation and regulation. Front Immunol. (2015) 6:262. doi: 10.3389/fimmu.2015.0026 
28. Angioi A, Fervenza FC, Sethi S, Zhang Y, Smith RJ, Murray $\mathrm{D}$, et al. Diagnosis of complement alternative pathway disorders. Kidney Int. (2016) 89:278-88. doi: 10.1016/j.kint.2015. 12.003

29. Michels MAHM, van de Kar NCAJ, Okrój M, Blom AM, van Kraaij SAW, Volokhina EB, et al. Overactivity of alternative pathway convertases in patients with complement-mediated renal diseases. Front Immunol. (2018) 9:612. doi: 10.3389/fimmu.2018.00612

30. Schramm EC, Roumenina LT, Rybkine T, Chauvet S, Vieira-Martins P, Hue $\mathrm{C}$, et al. Mapping interactions between complement C3 and regulators using mutations in atypical hemolytic uremic syndrome. Blood (2015) 125:2359-69. doi: 10.1182/blood-2014-10-609073

31. Forneris F, Wu J, Xue X, Ricklin D, Lin Z, Sfyroera G, et al. Regulators of complement activity mediate inhibitory mechanisms through a common C3b-binding mode. EMBO J. (2016) 35:1133-49. doi: 10.15252/embj.2015 93673

32. Esparza-Gordillo J, Goicoechea de Jorge E, Buil A, Carreras Berges L, López-Trascasa M, Sánchez-Corral P, et al. Predisposition to atypical hemolytic uremic syndrome involves the concurrence of different susceptibility alleles in the regulators of complement activation gene cluster in 1q32. Hum Mol Genet. (2005) 14:703-12. doi: 10.1093/hmg/ ddi066

33. Heurich M, Martinez-Barricarte R, Francis NJ, Roberts DL, Rodriguez de Cordoba S, Morgan BP, et al. Common polymorphisms in C3, factor $\mathrm{B}$, and factor $\mathrm{H}$ collaborate to determine systemic complement activity and disease risk. Proc Natl Acad Sci USA. (2011) 108:8761-6. doi: $10.1073 /$ pnas. 1019338108

34. Harris CL, Heurich M, Cordoba SR de, Morgan BP. The complotype: dictating risk for inflammation and infection. Trends Immunol. (2012) 33:513-21. doi: 10.1016/j.it.2012.06.001

35. Rother RP, Rollins SA, Mojcik CF, Brodsky RA, Bell L. Discovery and development of the complement inhibitor eculizumab for the treatment of paroxysmal nocturnal hemoglobinuria. Nat Biotechnol. (2007) 25:1256-64. doi: $10.1038 /$ nbt1344

36. Macia M, de Alvaro Moreno F, Dutt T, Fehrman I, Hadaya K, Gasteyger $\mathrm{C}$, et al. Current evidence on the discontinuation of eculizumab in patients with atypical haemolytic uraemic syndrome. Clin Kidney J. (2017) 10:310-9. doi: $10.1093 / \mathrm{ckj} / \mathrm{sfw} 115$
37. Guerra JC, de Castro CG, Campregher PV, Galvao T, Santos OP, Santos $\mathrm{BC}$, et al. Novel C3 mutation causing atypical hemolytic uremic syndrome successfully treated with eculizumab. Blood (2014) 124:1333. Available online at: http://www.bloodjournal.org/content/124/21/1333

38. Welte T, Arnold F, Kappes J, Seidl M, Häffner K, Bergmann C, et al. Treating C3 glomerulopathy with eculizumab. BMC Nephrol. (2018) 19:7. doi: 10.1186/s12882-017-0802-4

39. Jayne DRW, Bruchfeld AN, Harper L, Schaier M, Venning MC, Hamilton P, et al. Randomized trial of C5a receptor inhibitor avacopan in ANCA-associated vasculitis. J Am Soc Nephrol. (2017) 28:2756-67. doi: 10.1681/ASN.2016111179

40. Tesar V, Hruskova Z. Avacopan in the treatment of ANCAassociated vasculitis. Expert Opin Investig Drugs (2018) 27:491-6. doi: 10.1080/13543784.2018.1472234

41. Lubbers R, Essen MF van, Kooten C van, Trouw LA. Production of complement components by cells of the immune system. Clin Exp Immunol. (2018) 188:183-94. doi: 10.1111/cei.12952

42. Pasch MC, van den Bosch NHA, Bos JD, Asghar SS, Daha MR. Synthesis of Complement components $\mathrm{C} 3$ and factor B in human keratinocytes is differentially regulated by cytokines. J Invest Dermatol. (2000) 114:78-82. doi: 10.1046/j.1523-1747.2000.00841.x

43. Thomas A, Gasque P, Vaudry D, Gonzalez B, Fontaine M. Expression of a complete and functional complement system by human neuronal cells in vitro. Int Immunol. (2000) 12:1015-23. doi: 10.1093/intimm/12.7.1015

44. Jennette JC, Falk RJ. The role of pathology in the diagnosis of systemic vasculitis. Clin Exp Rheumatol. (2007) 25(1 Suppl 44):S52-56.

Conflict of Interest Statement: The authors declare that the research was conducted in the absence of any commercial or financial relationships that could be construed as a potential conflict of interest.

Copyright (C) 2018 Omoyinmi, Mohamoud, Gilmour, Brogan and Eleftheriou. This is an open-access article distributed under the terms of the Creative Commons Attribution License (CC BY). The use, distribution or reproduction in other forums is permitted, provided the original author(s) and the copyright owner(s) are credited and that the original publication in this journal is cited, in accordance with accepted academic practice. No use, distribution or reproduction is permitted which does not comply with these terms. 